\title{
Production of Superoxide Dismutase from Streptococcus lactis Using a Bioreactor with a Microfiltration Module
}

\author{
Masayuki Taniguchi, Isao Nakagawa, Kazuhiro Hoshino, \\ Takehiro ITOH, Koichi OHNO \\ and Michihiro FuJII \\ Department of Chemical Engineering, Faculty of Engineering, \\ * Graduate School of Natural Science and Technology, Nigata University, \\ Ikarashi 2, Nitgata 950-21, Japan
}

Received March 27, 1989

\begin{abstract}
The performance of a bioreactor with a microfiltration module for the production of an intracellular enzyme, superoxide dismutase (SOD), by Streptococcus lactis is described. The fermentation system involving the bioreactor enables the continuous removal of metabolites inhibitory for cell growth and the complete recycling of the cells to the bioreactor. In a fed-batch (FB) culture with filtration, in which the main metabolite, lactic acid, in the culture broth was maintained at a low concentration, $S$. lactis was cultivated to the high concentration of $15.5 \mathrm{~g}$-dry cells/l. The SOD content of the cells remained at almost a constant level throughout the cultivation and the productivity of SOD as well as cells per unit time was 4.3 -fold as high as that in the case of a conventional batch culture without filtration. Repeating the FB culture with filtration enhanced the productivities of SOD and cells further, as compared with those in the case of the FB culture with filtration.
\end{abstract}

Recently, the toxicity of the superoxide radical $\left(\mathrm{O}_{2}^{-}\right)$, resulting from the univalent reduction of molecular oxygen, and its metabolic products, such as hydrogen peroxide $\left(\mathrm{H}_{2} \mathrm{O}_{2}\right)$ and the hydroxyl radical $(\cdot \mathrm{OH})$, has attracted attention in medical science. ${ }^{1,2)}$ Superoxide dismutase (SOD, EC 1.15.5.5), which catalyzes the dismutation of superoxide radicals, plays a significant role in the enzymatic defense against the toxicity of active oxygen species. ${ }^{3,4}$ ) Hence, SOD is of potential interest in the pharmaceutical and food industries in situations where the action of $\mathrm{O}_{2}^{-}$may have a wide variety of deleterious effects.

Streptococcus lactis, a homofermentative lactic acid bacterium, contains a manganese SOD (Mn-SOD), ${ }^{5)}$ which might be advantageous for practical utilization because the strain is used as a safe microorganism for making dairy products, such as cheese and yogurt, and for improving the storage stability of meat, ${ }^{6}$ and $\mathrm{Mn}-\mathrm{SOD}$ is more stable against $\mathrm{H}_{2} \mathrm{O}_{2}$ at higher concentrations, as compared with $\mathrm{Cu}, \mathrm{Zn}$-SOD and $\mathrm{Fe}-\mathrm{SOD}{ }^{5}{ }^{5}$ Since Mn-SOD of S. lactis is an intracellular enzyme, enhancement of the cell mass productivity would make it possible to efficiently produce Mn-SOD. High concentration cultivation is considered to be one of the most effective methods for obtaining higher cell productivity. ${ }^{7,8)}$ We have recently established a fermentation system involving mechanical filtration with a ceramic filter ${ }^{9,10}$ ) or a microfiltration module ${ }^{11,12)}$ for highconcentration cultivation of microorganisms which themselves excrete growth inhibitors. With several microorganisms, Lactobacillus casei ${ }^{9)}$ Bifidobacterium longum, ${ }^{10)}$ Pediococcus halophilus ${ }^{11)}$ and Propionibacterium shermanii, ${ }^{12)}$ high cell productivities were successfully obtained by means of this fermentation system, in which inhibitory metabolites for cell growth are continuously removed and simultaneously fresh medium is continuously supplied. We report here on the production of intracellular SOD of S. lactis, which secretes inhibitory metabolites (mainly lactic acid) for cell growth, by means of the fed-batch (FB) cultivation method involving a bioreactor with 
a microfiltration module.

\section{Materials and Methods}

Microorganism and medium. Streptococcus lactis IFO 12007 was used throughout this study. The composition of the medium was $5 \%$ glucose, $1 \%$ Polypepton (Nippon Seiyaku Co.), $1 \%$ meat extract (Kyokuto Seiyaku Co.), $0.5 \%$ yeast extract (Oriental Yeast Co.), $0.5 \%$ sodium acetate, $0.2 \%$ ammonium citrate, $0.2 \% \mathrm{~K}_{2} \mathrm{HPO}_{4}, 0.1 \%$ Tween $80,0.075 \%$ L-cysteine, $0.0575 \% \mathrm{MgSO}_{4} \cdot 7 \mathrm{H}_{2} \mathrm{O}$ and $0.012 \% \mathrm{MnSO}_{4} \cdot 2 \mathrm{H}_{2} \mathrm{O}$. The $\mathrm{pH}$ of the medium was adjusted to 6.8 . The medium was sterilized by autoclaving at $121^{\circ} \mathrm{C}$ for $15 \mathrm{~min}$.

Inoculation. S. lactis was precultivated statically in test tubes containing $10 \mathrm{ml}$ of the medium. The precultivated cells were separated from the culture broth containing metabolites by centrifugation at $17,000 \times g$ for $10 \mathrm{~min}$ and then inoculated into fresh medium to an initial turbidity reading $(660 \mathrm{~nm})$ of $0.04 \sim 0.08$. This turbidity corresponds to $0.018 \sim 0.036 \mathrm{~g}$-dry cells $/ 1$

Batch culture. S. lactis was cultivated in test tubes or a bioreactor with a working volume of $0.7 \mathrm{l}$. Test tubes were used for examining the effect of the lactic acid concentration on cell growth. When the bioreactor was used, the $\mathrm{pH}$ of the medium was maintained at 6.8 by adding a $2 \mathrm{~N} \mathrm{NaOH}$ solution by means of a peristaltic pump connected to a $\mathrm{pH}$ controller. Nitrogen gas was sparged at $0.2 \mathrm{vvm}$ throughout the cultivation to maintain anaerobic conditions. Antifoam (Silicone KM-72; Shin-Etsu Kagaku Co.) was added to the culture medium when necessary.

$F B$ culture with filtration. The fermentation system described previously, ${ }^{11.12)}$ in which cross-flow filtration with a microfiltration module (Microza PW 103; Asahi Kasei Co.) allows continuous filtration of the culture broth, was used in this study. The culture broth was circulated with a roller pump (RP-30; Tokyo Rikakikai Co.). The filtration flux was controlled with a variablespeed peristaltic pump (Type 1011; Tokyo Rikakikai Co.). The same volume of fresh medium as the filtrate was replaced via a pump, which was coupled to a level controller to maintain a constant working volume in the bioreactor.

FB cultures with filtration were carried out by the following three methods. 1) FB cuitures with a constant dilution rate: The rates of filtration of culture broth and supply of fresh medium were kept at $0.7 \mathrm{l} / \mathrm{hr}$, which corresponds to a dilution rate $(D)$ of $1.0 \mathrm{hr}^{-1}$. 2) $\mathrm{FB}$ cultures with a stepwise increase in dilution rate: The rates of filtration of the culture broth and supply of fresh medium were increased stepwise from 0.35 to $1.4 \mathrm{l} / \mathrm{hr}$. 3) Repeated FB culture with a constant dilution rate: A FB culture with filtration was repeated five times. At the end of every FB culture with filtration, two-thirds $(0.467$ l) of the working volume was withdrawn and 0.4671 of fresh medium was simultaneously supplied. The time required for the replacement of the medium was $5 \sim 7 \mathrm{~min}$. The $D$ value was kept constant at $1.0 \mathrm{hr}^{-1}$ throughout the repeated FB cultures. In the repeated FB cultures, the microfiltration module was exchanged once for another one to prevent a decrease in the filtration rate.

Cell-free extract preparation. Cells were harvested by centrifugation at $17,000 \times g$ for $10 \mathrm{~min}$, washed in $50 \mathrm{~mm}$ potassium phosphate buffer ( $\mathrm{pH} 7.8$ ) containing $0.1 \mathrm{~mm}$ EDTA, and then resuspended in the same buffer. The cell suspension was stored at $-20^{\circ} \mathrm{C}$ till cell disruption. The cell suspension was diluted with the buffer to a turbidity reading of less than $1.0(660 \mathrm{~nm})$, followed by disintegration with a sonicator (INSONATOR Model 201M; Kubota Seisakusho Co.) at an output of $190 \mathrm{~W}$ for a total time of $10 \mathrm{~min}(5$ cycles of 2 min treatment and a 2 min interval). The cell debris was removed by centrifugation at $17,000 \times g$ for $10 \mathrm{~min}$. The supernatant was used as the cell-free extract for the enzyme assay.

Assay. SOD activity was measured at $25^{\circ} \mathrm{C}$ and $\mathrm{pH} 7.8$ by the method of Asada et al. ${ }^{13)}$ a system of xanthinexanthine oxidase for the generation of $\mathrm{O}_{2}^{-}$and a ferricytochrome $c$ (Sigma Chemical Co.) system as an electron acceptor being used. One unit of activity is defined as the quantity of the enzyme required to produced a $50 \%$ decrease in the rate of cytochrome $c$ reduction. Specific activities are expressed as units per gram of dry cell weight or protein. The cell concentration was determined by measuring the turbidity at $660 \mathrm{~nm}\left(\mathrm{~T}_{660}\right)$. Dry cell weight was determined by centrifuging a culture broth at $17,000 \times g$ for $10 \mathrm{~min}$, followed by drying of the cells at $90^{\circ} \mathrm{C}$ for more than $12 \mathrm{hr}$. Here, one unit of $\mathrm{T}_{660}$ corresponds to $0.441 \mathrm{~g}$-dry cells/1. The protein concentration was determined by the method of Lowry et al. ${ }^{14)}$ using bovine serum albumin as a standard. After centrifuging a culture broth at $17,000 \times g$ for $10 \mathrm{~min}$ to remove the cells, the supernatant obtained was analysed for glucose, lactic acid, acetic acid and formic acid. Residual glucose was determined using a Glucose C-Test kit (Wako Pure Chemical Industries Co.). The amount of lactic acid produced was determined by the method of Barker using p-phenylphenol. ${ }^{153}$ Formic acid was determined by the method Fukui using chromotropic acid. ${ }^{16)}$ Acetic acid was determined by gas-chromatography on a column packed with Chromosorb 101 (Gasukuro Kogyo Co.).

\section{Results and Discussion}

\section{Batch culture}

Figure 1 shows the results of a batch culture of $S$. lactis with the $\mathrm{pH}$ controlled at 6.8 . The bacterium grew logarithmically for the initial 


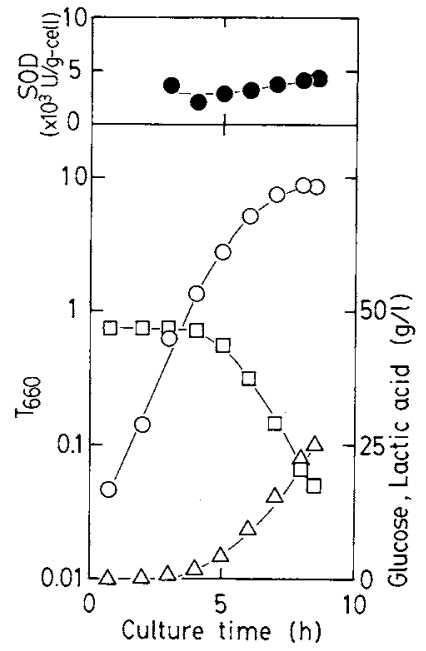

Fig. 1. Batch Culture of S. lactis.

The $\mathrm{pH}$ of the medium was maintained at 6.8. - SOD content of cells; $\bigcirc$, turbidity at $660 \mathrm{~nm} ; \square$, glucose; $\triangle$, lactic acid

$4 \mathrm{hr}$. Although glucose remained in the medium, the growth of $S$. lactis stopped after $8 \mathrm{hr}$. The final cell concentration obtained was $3.84 \mathrm{~g}$-dry cells $/ 1\left(\mathrm{~T}_{660}=8.7\right)$ and the final SOD concentration was $1.54 \times 10^{4} \mathrm{U} / 1$, which corresponds to $4.04 \times 10^{3} \mathrm{U} / \mathrm{g}$-dry cells. The weight ratio of lactic acid, the main metabolite, to glucose consumed was, on average, 0.88 . On organic acid analyses, acetic acid $(0.56 \mathrm{~g} / \mathrm{l})$ and formic acid $(0.14 \mathrm{~g} / 1)$ were detected in the medium at the culture time of $8 \mathrm{hr}$.

Figure 2 shows the inhibitory effect of the lactic acid concentration on the cell growth. To examine the initial specific growth rates, $S$. lactis was grown in test tubes containing fresh medium with various concentrations of lactic acid. The inhibitory effect was expressed as a ratio of the maximum specific growth rate $\left(\mu_{\max }=1.1 \mathrm{hr}^{-1}\right)$ obtained in fresh medium without lactic acid to the specific growth rate, $\mu$, under each condition. The initial growth rate was significantly influenced by the concentration of lactic acid. An initial concentration of lactic acid of more than $8 \mathrm{~g} / 1$ caused a great decrease in the growth rate. The ratio of $\mu / \mu_{\max }$ was about 0.1 when the bacterium

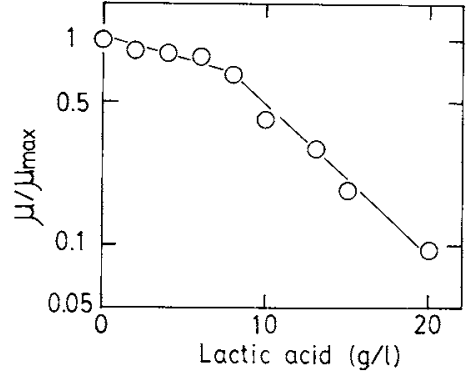

Fig. 2. Effect of the Initial Lactic Acid Concentration on the Specific Growth Rate of S. lactis.

was cultivated in the culture broth containing lactic acid at $20 \mathrm{~g} / \mathrm{l}$. The cell growth was found to be significantly inhibited by lactic acid, although the degree of growth inhibition by initially added lactic acid did not coincide completely with that by lactic acid accumulated in the batch culture (Fig. 1) because of growth inhibition by other factors, such as the accumulation of other metabolites (acetic and formic acids) and the exhaustion of components other than glucose in the medium.

\section{$F B$ culture with filtration}

Since SOD is produced and exists within cells, high cell concentration cultivation is expected to improve the SOD productivity. We applied a culture system with a hollow fiber module to remove lactic acid, a major growth inhibitor, continuously, and to attain a high cell concentration. Figure 3 shows the results of a FB culture with filtration at a constant filtration rate of $0.71 / \mathrm{hr}$. The filtration was started at the culture time of $5 \mathrm{hr}$ in the late-logarithmic growth phase. The removal of metabolites inhibitory for cell growth extended the logarithmic growth period until a culture time of $6 \mathrm{hr}$. However, a gradual decrease in the growth rate was observed after $6 \mathrm{hr}$, probably due to accumulation of metabolites with an increase in cell concentration. A dry cell concentration of $15.5 \mathrm{~g} / 1 \quad\left(\mathrm{~T}_{660}=\right.$ $35.1)$ and a SOD concentration of $6.62 \times$ $10^{4} \mathrm{U} / 1$ were obtained at the end of the culture $(10 \mathrm{hr})$. The cell and SOD concentrations were about 4-fold and 4.3-fold, respectively, of 


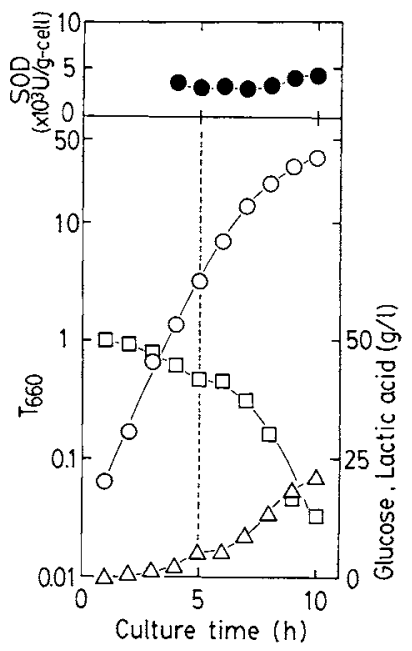

Fig. 3. Fed-batch Culture of $S$. lactis with a Constant Filtration Rate.

Filtration was started at a culture time of $5 \mathrm{hr}$ as indicated by the dotted line. The filtration rate was maintained at $0.7 \mathrm{l} / \mathrm{hr}$ from 5 to $10 \mathrm{hr}$. The same volume of fresh medium as the filtrate was supplied., SOD content; $O$, turbidity at $660 \mathrm{~nm} ; \square$, glucose; $\triangle$, lactic acid.

those in the case of the batch culture. The final SOD content of the cells was $4.27 \times 10^{3} \mathrm{U} / \mathrm{g}$ dry cells. No decrease in the SOD content was observed throughout the FB culture with filtration.

Figure 4 shows the results of a FB culture with a stepwise increase in the filtration rate. To enhance the cell productivity per culture time, the filtration rate of the fermentation broth was increased step by step in conjunction with cell growth while fresh medium was being supplied. This schedule was decided upon tentatively. As shown in Fig. 4, the bacterium grew vigorously and the final cell concentration at $11 \mathrm{hr}$ was $21.6 \mathrm{~g}$-dry cells/1 $\left(\mathrm{T}_{660}=49.0\right)$, i.e., 1.4-fold higher than that without a stepwise increase in the filtration rate (Fig. 3). The SOD concentration also increased with cell growth and reached $8.68 \times 10^{4}$ $\mathrm{U} / 1$ at $11 \mathrm{hr}$.

\section{Repeated FB culture with filtration}

The cell productivity per culture time in a batch fermentation is considered to be enhanced by increasing the inoculum size to

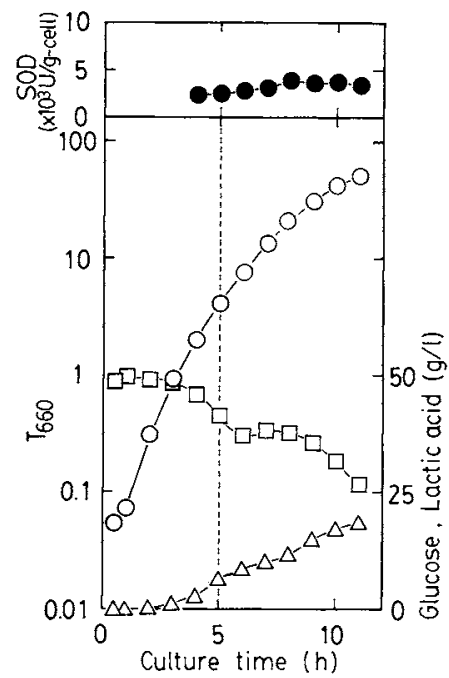

Fig. 4. Fed-batch Culture of S. lactis with a Stepwise Increase in the Filtration Rate.

Filtration was started at a culture time of $5 \mathrm{hr}$, as indicated by the dotted line. The filtration rate was increased in a stepwise manner: $0.351 / \mathrm{hr}(5 \sim 6 \mathrm{hr}) ; 0.7 \mathrm{l} / \mathrm{hr}(6 \sim 7 \mathrm{hr})$; $1.051 / \mathrm{hr}(7 \sim 8 \mathrm{hr}) ; 1.41 / \mathrm{hr}(8 \sim 11 \mathrm{hr})$. The same volume of fresh medium as the filtrate was supplied. SOD content of cells; $O$, turbidity at $660 \mathrm{~nm} ; \square$, glucose; $\triangle$, lactic acid.

shorten the lag-phase period and by reducing the down time required for preparation for the next batch fermentation, including washing of the bioreactor and sterilization of the medium, just as improvement of ethanol productivity was achieved by the repeated batch culture with a yeast cell reuse system. ${ }^{17)}$ We tried to repeat the $\mathrm{FB}$ culture with filtration to improve further the productivity of SOD as well as that of cells. Figure 5 shows the results of five repeated FB cultures with filtration. The filtration was started at a culture time of $5 \mathrm{hr}$ in the first FB culture. When the cell growth almost ceased at $10 \mathrm{hr}$ in the first FB culture with filtration, two-thirds of the culture broth containing cells was removed and replaced by the same amount of fresh medium. After the replacement, the $\mathrm{FB}$ culture with filtration was repeated four times for a total culture time of $20 \mathrm{hr}$. The volume ratio of culture broth withdrawn to the initially added broth was tentatively determined. In the middle $(18.3 \mathrm{hr})$ of the FB culture with filtration $(5 \sim 30 \mathrm{hr})$, the 


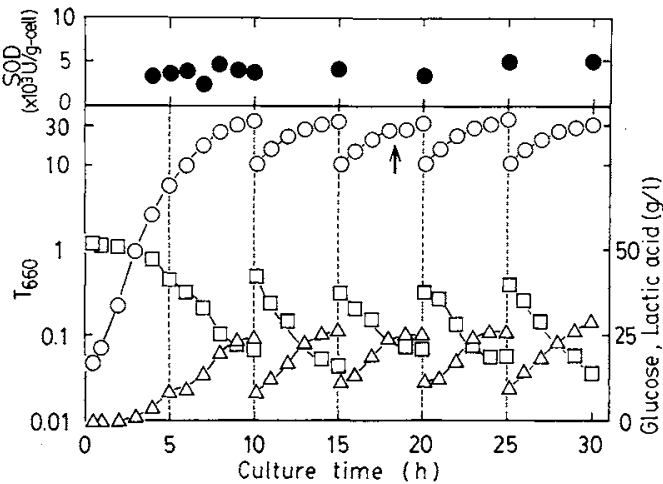

Fig. 5. Repeated Feci-batch Culture of S. lactis with a Constant Filtration Rate.

Filtration was started at $5 \mathrm{hr}$ in the first batch culture. The filtration rate was maintained at $0.7 \mathrm{l} / \mathrm{hr}$. The same volume of fresh medium as the filtrate was supplied. Two-thirds of the culture broth was replaced by the same volume of fresh medium at the end of each fed-batch culture. The microfiltration module was replaced by a new one at a culture time of $18.3 \mathrm{hr}$, as indicated by the arrow. SOD content; $O$, turbidity at $660 \mathrm{~nm} ; \square$, glucose; $\triangle$, lactic acid.

microfiltration module was replaced with another one to prevent a decrease in the filtration rate. The cell and SOD concentrations at the end of each FB culture with filtration were, on average, $14.6 \mathrm{~g}$-dry cells $/ 1 \quad\left(\mathrm{~T}_{660}=33.1\right)$ and $6.26 \times 10^{4} \mathrm{U} / 1$, respectively. In the repeated FB culture with filtration, the SOD content of the cells was almost as high as those in the case of the other cultures described above.

\section{Comparison of cell and SOD productivities}

Table I compares the cell and SOD productivities for different culture methods. Since little or no difference in SOD content per cell mass was observed among fermentations, as described above, SOD productivity per culture time, $P_{\mathrm{F}} / t$, was increased by enhancing the cell mass productivity, $X_{\mathrm{F}} / t$, where $P_{\mathrm{F}}, X_{\mathrm{F}}$ and $t$ are the SOD and cell concentrations at the end of each culture, and the culture time, respectively. The SOD activities per amount of protein in cell-free extracts obtained at the end of the cultures were almost constant $(7.1 \sim 8.9 \times$ $10^{3} \mathrm{U} / \mathrm{g}$-protein). This means that physical stress due to circulation of the broth may have no effect on SOD production by $S$. lactis.
We also compared the SOD productivities of the FB culture with filtration (Run 2, Fig. 3) and the repeated FB culture with filtration (Run 4, Fig. 5). Taking into account the volume of culture broth removed at the end of each FB culture as well as the total culture time, the SOD productivity in Run 4, $P_{\mathrm{RB}}$ (SOD), can be expressed by the following equation:

$$
\begin{array}{r}
P_{\mathrm{RB}}(\mathrm{SOD})=\bar{P}_{\mathrm{F}}\left\{(n-1) \cdot f \cdot V_{0}+V_{0}\right\} / \\
\left\{t_{\mathrm{b}}+(n-1)\left(t_{\mathrm{p}}+t_{\mathrm{r}}\right)+t_{\mathrm{h}}\right\}
\end{array}
$$

where $\bar{P}_{\mathrm{F}}, n, f$ and $V_{0}$ are the average SOD concentration, the number of FB culture cycles, the discharge fraction (volume ratio of culture broth withdrawn to the initially added broth) and the initial working volume, respectively. The total culture time, $t$, was assumed to be divided into $t_{\mathrm{b}}$ (culture time for the first FB culture with filtration), $t_{\mathrm{p}}$ (culture time for the $n$-th FB culture with filtration), $t_{\mathrm{r}}$ (time required for replacing the culture broth with fresh medium) and $t_{\mathrm{h}}$ (time required for harvesting the cells). On the other hand, the SOD productivity of the usual FB culture with filtration (Run 2), $P_{\mathrm{B}}$ (SOD), can be expressed as Eq. (2).

$$
P_{\mathrm{B}}(\mathrm{SOD})=P_{\mathrm{F}} \cdot V_{0} /\left(t_{\mathrm{b}}+t_{\mathrm{h}}\right)
$$

Here, when $t_{\mathrm{h}}$ was assumed to be zero for convenience and the two productivities were calculated using $\bar{P}_{\mathrm{F}}=6.26, P_{\mathrm{F}}=6.62, f=2 / 3$, $n=5, t_{\mathrm{b}}=10 \mathrm{~h}, t_{\mathrm{p}}=4.9 \mathrm{~h}$ and $t_{\mathrm{r}}=0.1 \mathrm{~h}$, on the basis of the results in Runs 2 and 4, the ratio of $P_{\mathrm{RB}}(\mathrm{SOD}) / P_{\mathrm{B}}(\mathrm{SOD})$ was 1.16 . If $n$ is 20 , the ratio is 1.23 . This means that an increase in $n$ more effectively enhances the ratio of $P_{\mathrm{RB}}(\mathrm{SOD}) / P_{\mathrm{B}}(\mathrm{SOD})$. When $n$ is constant, $P_{\mathrm{RB}}(\mathrm{SOD})$ may be enhanced by increasing $f$, although $t_{\mathrm{r}}$ and $t_{\mathrm{p}}$ become greater due to removal of a larger amount of culture broth and lowering of the initial cell concentration. Apart from the inherent problem of a decrease in filtration rate in the case of using membranes, it is necessary to study the growth properties in order to determine the optimum operation conditions. Now, studies on the 
Table I. Comparison of Cell and SOD Productivities

\begin{tabular}{|c|c|c|c|c|c|c|c|c|c|c|c|c|}
\hline \multirow{3}{*}{$\begin{array}{l}\text { Run } \\
\text { No. }\end{array}$} & \multirow{3}{*}{$\begin{array}{l}\text { Cultivation } \\
\text { method }\end{array}$} & \multirow{3}{*}{$\begin{array}{c}\text { Cultivation } \\
\text { time } \\
t \\
(\mathrm{hr})\end{array}$} & \multirow{3}{*}{$\begin{array}{l}\text { Total volume } \\
\text { of } \\
\text { medium used } \\
V \\
\text { (l) }\end{array}$} & \multicolumn{2}{|c|}{ Dry cell } & \multicolumn{2}{|c|}{ SOD } & \multirow{3}{*}{$\begin{array}{c}\text { SOD } \\
\text { content } \\
\left(\times 10^{3} \mathrm{U} /\right. \\
\text { g-cell })\end{array}$} & \multicolumn{4}{|c|}{ Productivity } \\
\hline & & & & \multirow{2}{*}{$\begin{array}{c}\mathrm{C} \\
X_{\mathrm{F}} \\
(\mathrm{g} / \mathrm{l})\end{array}$} & \multirow{2}{*}{$\begin{array}{c}\text { TA } \\
X_{\mathrm{F}} \cdot V_{0}{ }^{11} \\
\quad(\mathrm{~g})\end{array}$} & \multirow{2}{*}{$\begin{array}{c}\mathrm{C} \\
P_{\mathrm{F}} \\
\left(\times 10^{4} \mathrm{U} / 1\right)\end{array}$} & \multirow{2}{*}{$\begin{array}{c}\text { TA } \\
P_{\mathrm{F}} \cdot V_{0} \\
\left(\times 10^{4} \mathrm{U}\right)\end{array}$} & & \multicolumn{2}{|c|}{ Dry cell } & \multicolumn{2}{|c|}{ SOD } \\
\hline & & & & & & & & & $\begin{array}{c}X_{\mathrm{F}} / t \\
(\mathrm{~g} / \mathrm{l} / \mathrm{hr})\end{array}$ & $\begin{array}{c}\left(X_{\mathrm{F}} \cdot V_{\mathrm{o}}\right) / t \\
(\mathrm{~g} / \mathrm{hr})\end{array}$ & $\begin{array}{c}P_{\mathrm{F}} / t \\
\left(\times 10^{3} \mathrm{U} / \mathrm{H} / \mathrm{hr}\right)\end{array}$ & $\begin{array}{c}\left(P_{\mathrm{F}} \cdot V_{0}\right) / t \\
\left(\times 10^{3} \mathrm{U} / \mathrm{hr}\right)\end{array}$ \\
\hline 1 & Batch $^{a}$ & 8 & $0.7(-)^{b}$ & 3.84 & 2.69 & 1.54 & 1.08 & 4.04 & 0.480 & 0.336 & 1.94 & 1.36 \\
\hline 2 & This method ${ }^{c}$ & 10 & $4.2(3.5)$ & 15.5 & 10.9 & 6.62 & 4.63 & 4.27 & 1.55 & 1.09 & 6.62 & 4.63 \\
\hline 3 & This method ${ }^{d}$ & 11 & $7.0(6.3)$ & 21.6 & 15.1 & 8.68 & 6.08 & 4.02 & 1.96 & 1.37 & 7.88 & 5.52 \\
\hline 4 & This method ${ }^{e}$ & 30 & $20.0(17.5)$ & $14.6^{f}$ & $(37.6)^{g}$ & $6.26^{f}$ & $(16.1)^{g}$ & 4.29 & - & $(1.25)^{h}$ & - & $(5.37)^{h}$ \\
\hline
\end{tabular}

a Data were obtained for a batch culture with a working volume of $V_{0}=0.71$ (Fig. 1)

$b$ Total volume of filtrate.

Data were obtained for a batch culture with filtration (Fig. 3). The filtration rate was maintained at $0.71 / \mathrm{hr}$ for $5 \mathrm{hr}$.

d Data were obtained for a batch culture with filtration (Fig. 4). The filtration rate was increased in a stepwise manner from 0.35 to $1.41 / \mathrm{hr}$ for $6 \mathrm{hr}$.

e Data were obtained from a repeated batch culture with filtration (Fig. 5). The filtration rate was maintained at $0.71 / \mathrm{hr}$ for $25 \mathrm{hr}$.

$f$ Data are the averages of values obtained at the end of each batch culture.

$g$ Data show the total amount obtained in a repeated batch culture with filtration.

$h$ Values were calculated on the basis of the total amount obtained on a repeated batch culture with filtration (Eq. (1)).

C, concentration; TA, total amount. 
growth characteristics of the bacterium are in progress.

In the culture with filtration, a large amount of fresh medium was supplied. This reduces the efficiency as to utilization of nutrients in the medium. For precise comparison of SOD productivity, i.e., cell productivity, among different cultivation procedures with respect to not only the time required for cell mass production but also the cost of the medium components, the SOD productivity should be expressed as $P_{\mathrm{F}} /(t \cdot V)$, as described previously, ${ }^{11)}$ where $V$ denotes the total volume of medium used. In the FB culture with filtration, the cell productivity, $P_{\mathrm{F}} /(t \cdot V)$, when the volume of medium used is considered, was approximately one-half for Run 2 and two-fifths for Run 3, as compared with that in the case of the batch culture (Run 1). Moreover, when the total amount of SOD per culture time was divided by $V$ for comparison of the SOD productivity between Runs 1 and 4 , the SOD productivity was $1.94 \times 10^{3} \mathrm{U} /(\mathrm{l} \cdot \mathrm{hr})$ for Run 1 and $2.69 \times$ $10^{2} \mathrm{U} /(1 \cdot \mathrm{hr})$ for Run 4. However, the low productivities, when the volume of medium used as well as the culture time is considered, could be overcome to some extent by using an on-line glucose analyzer and by controlling the acid concentration in the fermentor as reported recently. ${ }^{18,19)}$ Consequently, the most effective culture method should be selected on the basis of the difference between the value of a product and the cost of production.

A FB fermentation system involving a bioreactor was developed, in which inhibitory metabolites are continuously removed by cross-flow filtration through a microfiltration module. This system allowed complete retention of the cells in the bioreactor as well as continuous removal of metabolites inhibitory for cell growth. By using the bioreactor, up to $6.62 \times 10^{4} \mathrm{U} / 1$ of SOD was produced, corresponding to SOD productivity per unit time of 4.3-fold greater than that of the conventional batch culture without filtration. We demonstrated experimentally that the SOD productivity was enhanced further by repeating the FB culture with filtration, as compared with that of the FB culture with filtration.

Acknowledgments. The authors wish to thank Dr. T. Kobayashi, Professor of Nagoya University, for his kind support and suggestions, and Dr. A. Ohkawa, Professor of Niigata University, for critical reading of the manuscript. This work was supported in part by a Grant-in-Aid from the Mishima Kaiun Memorial Foundation.

\section{References}

1) M. Brunori and G. Rotilio, Methods in Enzymol, 105, 22 (1984).

2) I. Fridovich, Arch. Biochem. Biophys., 247, 1 (1986).

3) J. M. McCord and I. Fridovich, J. Biol. Chem., 244, 6049 (1969).

4) K. Asada, Seikagaku, 48, 226 (1976).

5) T. Kirby, J. Blum, I. Kahane and I. Fridovich, Arch. Biochem. Biophys., 201, 551 (1980).

6) T. Morichi, New Food Industry, 28, No. 2 , 1 (1986).

7) E. Ohleyer, H. W. Blanch and C. R. Wilke, Appl. Biochem. Biotechnol., 11, 317 (1985).

8) T. Yamane, P. Sirirote and S. Shimizu, J. Ferment. Technol., 66, 93 (1988).

9) M. Taniguchi, N. Kotani and T. Kobayashi, $J$. Ferment. Technol., 65, 179 (1987).

10) M. Taniguchi, N. Kotani and T. Kobayashi, Appl. Microbiol. Biotechnol., 25, 434 (1987).

11) M. Taniguchi, K. Hoshino, K. Shimizu, I. Nakagawa, Y. Takahashi and M. Fujii, J. Ferment. Technol., 66, 633 (1988).

12) H. Hatanaka, E. Wang, M. Taniguchi, S. Iijima and T. Kobayashi, Appl. Microbiol. Biotechnol., 27, 470 (1988).

13) K. Asada, M. Takahashi and M. Nagata, Agric. Biol. Chem., 34, 471 (1974).

14) O. H. Lowry, N. J. Rosebrough, A. J. Farr and R. J. Randall, J. Biol. Chem., 193, 265 (1951).

15) S. B. Barker, Methods in Enzymol,, 3, 241 (1957).

16) S. Fukui, Tanpakushitsu Kakusan Koso, 2, 365 (1957).

17) Y. Nishizawa, Y. Mitani, K. Fukunishi and S. Nagai, J. Ferment. Technol., 62, 41 (1984).

18) S. Mizutani, S. Iijima, M. Morikawa, K. Shimizu, M. Matsubara, Y. Ogawa, R. Izumi, K. Matsumoto and T. Kobayashi, J. Ferment. Technol., 65, 325 (1987).

19) E. Wang, H. Hatanaka, S. Iijima, T. Takebayashi, $Z$. Shi, K. Shimizu, M. Matsubara and T. Kobayashi, $J$. Chem. Eng. Japan, 21, 36 (1988). 